\title{
Photosynthetic performance of surface-associated algae below sea ice as measured with a pulse-amplitude-modulated (PAM) fluorometer and $\mathrm{O}_{2}$ microsensors
}

\author{
Michael Kühl ${ }^{1, *}$, Ronnie N. Glud ${ }^{1}$, Jens Borum ${ }^{2}$, Rodney Roberts ${ }^{3}$, Søren Rysgaard ${ }^{4}$ \\ ${ }^{1}$ Marine Biological Laboratory, University of Copenhagen, Strandpromenaden 5, 3000 Helsingør, Denmark \\ ${ }^{2}$ Freshwater Biological Laboratory, University of Copenhagen, Helsingørsgade 51, 3400 Hillerød, Denmark \\ ${ }^{3}$ Cawthron Institute, Private Bag 2, Nelson, New Zealand \\ ${ }^{4}$ Department of Lake and Estuarine Ecology, National Environmental Research Institute, Vejlsøvej 25, 8600 Silkeborg, Denmark
}

\begin{abstract}
The photosynthetic performance of sea ice microalgae, benthic microalgae, coralline red algae (Phymatolithon foecundum) and brown macroalgae (Laminaria saccharina, Fucus evanescens and Desmarestia aculeata) in an ice-covered high-Arctic fjord (Young Sound, NE Greenland) was studied with in situ instruments for oxygen microprofiling and active chlorophyll fluorescence measurements. In situ measurements of the effective quantum yield of Photosystem II (PSII) under ambient low irradiance ranged between 0.3 and 0.7 . Net oxygen production of benthic microalgae and sea ice microalgae was measured in situ at low irradiance of $\sim 2$ to $30 \mu \mathrm{mol}$ photons $\mathrm{m}^{-2} \mathrm{~s}^{-1}$. The compensation irradiance determined in the laboratory for coralline algae and brown macroalgae was 1.6 and $1.9 \mu \mathrm{mol}$ photons $\mathrm{m}^{-2} \mathrm{~s}^{-1}$ respectively. The same experiments showed irradiances at onset of saturation, $E_{\mathrm{k}}$ for coralline red algae and brown macroalgae of 17 and $12.8 \mu \mathrm{mol}$ photons $\mathrm{m}^{-2} \mathrm{~s}^{-1}$ respectively. In situ measurements of rapid light curves, measured over 1 to 2 min by the saturation pulse method, enabled snap shots of the in situ adaptation of the photosynthetic apparatus in the different phototrophs under ambient irradiance conditions. These measurements showed $\mathrm{E}_{\mathrm{k}}$ values for PSII related electron transport (relative ETR) at 7.9 (sea ice microalgae), 4.6 (benthic microalgae), 11 (coralline red algae) and 4.4 to 7.3 (brown macroalgae) $\mu \mathrm{mol}$ photons $\mathrm{m}^{-2} \mathrm{~s}^{-1}$. At higher irradiance levels, relative ETR decreased, indicating inhibition and/or downregulation of photosynthesis. When light curves were measured with longer application of the different actinic light levels, a less pronounced or zero decrease of relative ETR was found at higher irradiance, and $\mathrm{E}_{\mathrm{k}}$ values were shifted to higher irradiance, i.e. $6.9 \mu \mathrm{mol}$ photons $\mathrm{m}^{-2} \mathrm{~s}^{-1}$ (benthic microalgae) and 11.5 to $16.1 \mu \mathrm{mol}$ photons $\mathrm{m}^{-2} \mathrm{~s}^{-1}$ (brown macroalgae). This apparent short-term acclimation to increasing irradiance reversed to the initial characteristics of the light curve within 15 to $20 \mathrm{~min}$ after irradiance returned to ambient intensity. Our measurements add to the small database on in situ photosynthetic performance of surface-associated algae below ice cover. All phototrophs were well adapted to low irradiance under the ice, and active fluorescence measurements indicated that the phototrophs are able to adapt reversibly within minutes to moderate changes in irradiance levels.
\end{abstract}

KEY WORDS: Arctic $\cdot$ Sea ice $\cdot$ Microalgae $\cdot$ Macroalgae $\cdot$ Fluorescence $\cdot$ Oxygen $\cdot$ Microsensor $\cdot$ Photosynthesis Resale or republication not permitted without written consent of the publisher

\section{INTRODUCTION}

Phototrophic organisms associated with surfaces in polar marine environments experience an extreme light climate ranging from months of permanent dark-

(C) Inter-Research $2001 \cdot$ www.int-res.com ness, over very low irradiance under ice cover, to high and (in shallow waters) potentially damaging radiation stress in open water periods with almost continuous daylight. The main groups of surface associated phototrophs in the Arctic are: (1) macroalgae (mostly

*E-mail: mkuhl@zi.ku.dk 
brown and red algae including coralline algae), and (2) microalgae (largely diatoms) growing on the sea floor, as epiphytes on macroalgae, and in the lower part of sea ice as epontic microalgae. The groups of phototrophs mentioned are amongst the most productive in aquatic systems yet their importance as primary producers in polar ecosystems is still unclear (Horner \& Schrader 1982, Booth 1984). Few in situ investigations of algal photosynthesis in ice covered systems have been reported, and most have used ${ }^{14} \mathrm{C}$ incubations under or within the ice (e.g. Matheke \& Horner 1974, Andersen 1977, Booth 1984, Smith \& Herman 1991, Mock \& Gradinger 1999). This has largely been due to lack of suitable in situ technology, but has also been attributed to the difficulties and risks involved with SCUBA diving based methods in ice-covered regions.

Oxygen microsensors allow fine-scale studies of photosynthesis and respiration in both micro- and macroalgae (Sand-Jensen \& Revsbech 1987, Lassen et al. 1994, Kühl et al. 1996). Special instruments (i.e. profiling landers) have been developed for in situ measurements with oxygen microsensors. However, such instruments have mainly been used for measurements of oxygen consumption in biogeochemical studies of coastal or deep-sea sediments (reviewed in Reimers \& Glud 2000), and only a few studies have been performed in situ on photosynthetic systems (e.g. Wenzhöfer et al. 2000). Recently, the first in situ application of oxygen microsensors on communities of sea ice microalgae in the Antarctic was reported (McMinn et al. 2000). We are not aware of other in situ applications of oxygen microsensors for photosynthesis studies in ice-covered polar regions.

While originally developed in plant physiology, techniques for measurements of active chlorophyll fluorescence have, in the past $10 \mathrm{yr}$, become a new standard tool for assessment of aquatic photosynthesis (Falkowski \& Kolber 1993, Kolber \& Falkowski 1993, Schreiber et al. 1994, 1995, Falkowski \& Raven 1997). Van Kooten \& Snel (1990) defined the most widely used nomenclature for chlorophyll fluorescence parameters, which is also used in this paper. Two different techniques are used in aquatic systems: (1) the 'pump and probe method', which uses fast repetition rate fluorometers (Falkowski et al. 1986), and (2) the 'saturation pulse method', based on the use of pulse-amplitude-modulated (PAM) fluorometers (Schreiber et al. 1986, Bolhar-Nordenkampf et al. 1989). The latter method was used in the present study.

In situ measurements of active fluorescence in shallow waters have become possible with the development of a PAM fluorometer (Diving-PAM, Walz $\mathrm{GmbH}$, Effeltrich, Germany) and a fast-repetition-rate fluorometer (Gorbunov et al. 2000), which can both be operated under water by a SCUBA diver. The DivingPAM has mostly been used for in situ studies of seagrasses (Ralph et al. 1998, Beer \& Björk 2000), corals and other symbioses in reef communities (Beer et al. 1998, Ralph et al. 1999). Gorbunov et al. (2000) also tested their instrument in different warm water systems. Applications in polar regions have, to our knowledge, been limited to Diving-PAM studies of macroalgae in shallow open waters (D. Hanelt pers. comm.).

Here we demonstrate the first use of a Diving-PAM fluorometer for in situ photosynthesis studies under sea ice, in combination with a new instrument for in situ measurements of oxygen microprofiles at sea ice/water and sediment/water interfaces. This involved both SCUBA-diver operation and interactive online communication with the instruments from the sea ice surface. We present and discuss the potential of the techniques along with the first data on the oxygen microenvironment and photosynthetic performance in situ of the major surface associated algae in an icecovered Arctic fjord. In addition, results from laboratory studies under controlled in situ-like conditions are presented. Our goal was to get an overview of the photosynthetic performance of the different surfaceassociated algae in relation to available irradiance under ice cover. It was not our aim to present complete carbon budgets of the phototrophs investigated. In a companion paper (Rysgaard et al. 2001) a detailed seasonal study of sea ice algal distribution and activity is presented, which is largely based on the techniques described in the present paper.

\section{MATERIALS AND METHODS}

Site description. The study was carried out in the eastern part of the ice-covered Young Sound, northeastern Greenland, from 7 June to 5 July 1999. Our measurements were taken at Station A (74 ${ }^{\circ} 18^{\prime} 59^{\prime \prime} \mathrm{N}$, $20^{\circ} 15^{\prime} 04^{\prime \prime} \mathrm{W} ; 36 \mathrm{~m}$ water depth) and Station C

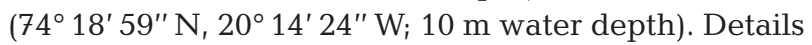
of the biogeochemistry and biology of Young Sound can be found elsewhere (Rysgaard et al. 1998, 1999, Glud et al. 2000b). Measurements were made under the sea ice via placement of equipment by SCUBA divers. The divers and in situ equipment entered through holes in the ice $(\sim 1 \mathrm{~m}$ in diameter $)$ made with a motor-driven ice drill and by manual cutting. Besides microalgae (mainly large diatoms) growing at the water-ice interface, extensive areas of the sea floor were coated by a brown biofilm of benthic pennate diatoms occurring from $\sim 5$ to $35 \mathrm{~m}$ depth. Dense beds of macroalgae (mostly Laminaria saccharina, Fucus evanescens and Desmarestia aculeata) were present at $\sim 5$ to $20 \mathrm{~m}$ depth, while stones covered with coralline 
red algae were common on the sea floor at 15 to $40 \mathrm{~m}$ depth.

Prevailing downwelling quantum irradiance (400 to $700 \mathrm{~nm}$ ) directly below the sea ice and on the sea floor was measured by an LI-192SA underwater irradiance sensor (LiCor, Lincoln, NE) connected via an underwater cable to a light meter (LiCor LI-1000) on the ice surface. Alternatively, the calibrated irradiance sensor of the Diving-PAM (see below) was used. Scalar irradiance, water temperature and salinity in the water column were measured with a CTD-probe (Datasonde r4, Hydrolab Corp., Austin, TX). Furthermore, the salinity of water collected with a syringe at the waterice interface was determined with a hand-held refractometer (Atago, Tokyo, Japan).
Oxygen measurements. In situ measurements of oxygen concentration profiles were made with Clarktype oxygen microsensors (Revsbech 1989) mounted directly on a waterproof electronics cylinder containing a picoammeter measuring circuit (Unisense A/S, Aarhus, Denmark). The microsensors had measuring tip diameters of 40 to $100 \mu \mathrm{m}$ and a low stirring sensitivity of $\leq 1 \%$ to $2 \%$ (Glud et al. 2000a). The complete microsensor/electronics unit was mounted on a motordriven spindle that was fixed to a metal tripod (Fig. 1) (KC, Silkeborg, Denmark). The tripod legs were equipped with closed tanks. Filling the tanks with different amounts of water regulated the buoyancy of the lander. For use on the sea floor, the tanks were filled completely with water; this kept the tripod in place

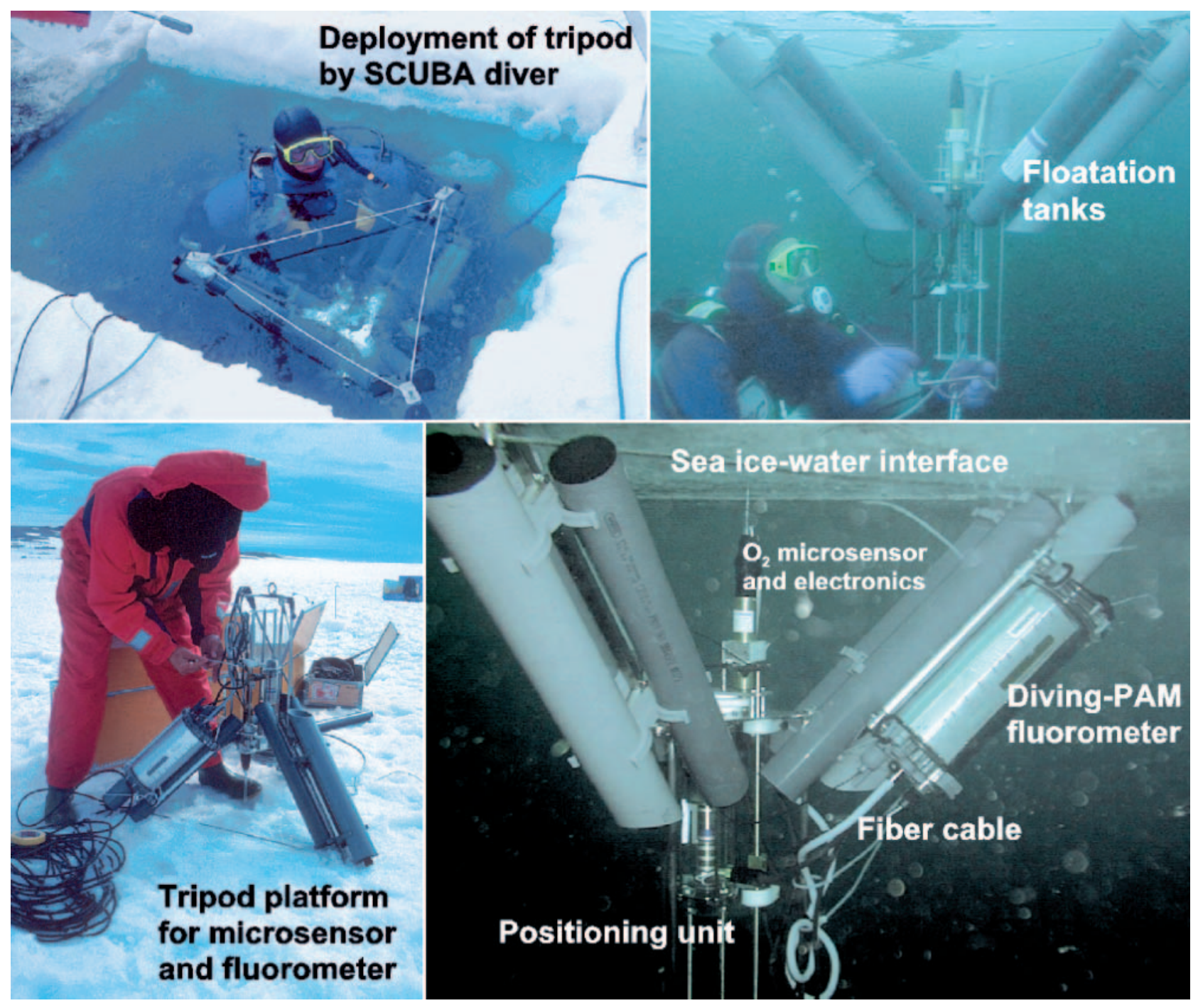

Fig. 1. A lander instrument for in situ measurements of oxygen microprofiles and active chlorophyll fluorescence below sea ice. Photographs show overall lander appearance and its components, and deployment of the lander via an ice hole by a diver. See text for details on lander operation. More pictures of the lander and its deployment under ice are available at http://www.dmu.dk/LakeandEstuarineEcology/CAMP 
during measurements. For use at the water-ice interface, the tripod was used upside down. The diver filled the tripod tanks with air from his breathing apparatus after positioning the tripod at the measuring position. The tanks now served as flotation units that pressed the tripod against the ice, keeping it stable and in place even in the presence of strong currents. For measurements at the water-ice interface, care was taken to avoid accumulation of air bubbles from the divers in the measuring area.

Sensor readout and motor control was achieved with an electronics control unit at the sea ice surface via a $50 \mathrm{~m}$ long underwater cable. Sensor signals were stored on a battery-driven strip-chart recorder (Servogor 110-2, Kipp \& Zonen, Delft, The Netherlands). The oxygen microsensors were linearly calibrated from 0 readings in surface water made anoxic by addition of sodium dithionite, and from readings in air-saturated seawater at known in situ temperature and salinity. The in situ measurements did not allow visual control of when the microsensor reached the surface of the ice or the sediment. Thus we defined the surface as the position of the steepest oxygen gradient in the measured microprofiles.

In addition to the in situ measurements, macroalgae and coralline red algae were studied with oxygen microsensors in the laboratory at near in situ temperatures by use of a thermostat, and under controlled light conditions by use of a tungsten halogen lamp (Schott, Mainz, Germany) and neutral density filters. For microprofiling, an oxygen microsensor was mounted in a motorized micromanipulator (Märtzhäuser/LOT-ORIEL, Germany), which was connected to a pA-meter (PA2000, Unisense A/S) and a Personal Computer (Toshiba T3200, Japan) equipped with an A/D-data acquisition card (Computer Boards Inc., USA) and a custom-built motor controller card. Steady state oxygen profiles were measured after 10 to 20 min incubation at each experimental irradiance. The microsensor position relative to the surface was determined visually by help of a dissection microscope.

Rates of net photosynthesis $\left(P_{n}\right)$ were calculated from steady state oxygen microprofiles as the net efflux of $\mathrm{O}_{2}$ using Fick's first law (Jørgensen \& Revsbech 1985):

$$
P_{\mathrm{n}}=-\mathrm{D}_{0}(\mathrm{~d} C / \mathrm{d} z)
$$

where $(\mathrm{d} C / \mathrm{d} z)$ is the linear slope of the oxygen concentration profile in the Diffusive Boundary Layer (DBL) and $\mathrm{D}_{0}$ is the molecular diffusion coefficient of oxygen. The oxygen concentration of seawater was determined by Winkler titration of water samples. The molecular diffusion coefficient of oxygen was taken from Broecker \& Peng (1974) and corrected for in situ and experimental temperatures as described by Li \& Gregory (1974).

Active fluorescence and the saturation pulse method. The saturation pulse method is based on sample illumination with weak, modulated, probing pulses for monitoring chlorophyll fluorescence without inducing any significant actinic effect of the measuring light. By this technique, fluorescence measurements can be carried out independent of the actinic light, which can be orders of magnitude higher (Schreiber et al. 1986). At environmental temperatures, chlorophyll fluorescence is mainly due to photosystem II (PSII) and its antenna pigments (Barber et al. 1989). In the dark-adapted state, a minimal fluorescence, $F_{0}$, is measured when turning on the measuring light. This weak fluorescence emission is mainly due to emission from antenna pigments (Krause \& Weis 1991). The $F_{0}$ variable has been used as a proxy for biomass, e.g. in studies of microphytobenthos distribution on intertidal sediments (Serodio et al. 1997).

When the sample is exposed to actinic light, a higher PSII fluorescence is observed, which exhibits a transient behavior over time until a steady state level of fluorescence $F$ is attained. This induction curve is known as the Kautsky curve and reflects: (1) variations in the redox state of the secondary electron acceptor pool, $Q_{\mathrm{a}}$, in the electron transport chain between PSII and PSI; and (2) complex interactions of non-photochemical processes and physical factors related to variations of the absorption cross-section of PSII.

Complete closure of PSII (i.e. full reduction of $Q_{\mathrm{a}}$ ) by application of a very intense saturation pulse to a darkadapted sample, leads to a maximal fluorescence, $F_{\mathrm{m}}$. Similarly, a saturation pulse applied under steady state actinic light conditions, when $Q_{\mathrm{a}}$ is partly reduced, leads to a maximal fluorescence $F^{\prime}{ }_{\mathrm{m}}$. Immediately after turning off actinic light and in the presence of far red light, which is predominantly absorbed by PSI, all PSII reaction centers are reopening as the $Q_{\mathrm{a}}$ pool is reoxidized by the drag of electrons towards PSI. This is seen as a minimal fluorescence $F_{0}^{\prime}$, which over time approaches the initial $F_{0}$ level. A useful variable, which is easy to measure in situ without the need for previous $F_{0}$ and $F_{0}^{\prime}$ determination, is the quantum yield of charge separation in PSII, $\phi_{\mathrm{p}}$, which can be determined as (Genty et al. 1989):

$$
\phi_{\mathrm{p}}=\left(F_{\mathrm{m}}^{\prime}-F\right) / F_{\mathrm{m}}^{\prime}
$$

Photosynthetic charge separation and $\mathrm{O}_{2}$ production are closely coupled, and a correlation between $\phi_{\mathrm{p}}$ and the quantum yield for $\mathrm{O}_{2}$ production, $\phi_{\mathrm{O}_{2}}$ can be expected. A good correlation between oxygen production and PSII electron transport was found in both microalgae and macroalgae (Henley 1993, Kolber \& Falkowski 1993, Hanelt et al. 1995, Hartig et al. 
1998). However, under non-optimal high irradiance the relationship becomes non-linear, and highly variable $\phi_{\mathrm{O}_{2}}: \phi_{\mathrm{p}}$ ratios are observed (Flameling \& Kromkamp 1998). Clearly, there is a need for more studies of the correlation between $\phi_{\mathrm{p}}$ and $\phi_{\mathrm{O}_{2}}$ in microalgae, and of how the correlation is affected by the light climate and other environmental variables. A close relationship between $\phi_{\mathrm{p}}$ and the quantum yield of carbon fixation is not to be expected, as PSI can exhibit cyclic electron transport and reducing equivalents at the acceptor side of PSI can be channeled into processes other than carbon fixation, e.g. nutrient uptake.

The photosynthetic Electron Transport Rate (ETR) between PSII and PSI can be calculated as:

$$
\mathrm{ETR}=\phi_{\mathrm{p}} \sigma_{\mathrm{a}} E_{0}(\mathrm{PAR})
$$

where $\sigma_{a}$ is the absorption cross-section of PSII, and $E_{0}(\mathrm{PAR})$ is the scalar irradiance of photosynthetically active radiation. $\sigma_{\mathrm{a}}$ cannot be determined directly with the saturation pulse method, but can be estimated with the pump and probe technique (Kolber \& Falkowski 1993). Relative ETR can be estimated as $\phi_{\mathrm{p}} \times E_{0}(\mathrm{PAR})$ under the assumption of a constant $\sigma_{\mathrm{a}}$ during the measurements (Hofstraat et al. 1994).

Normally, $P$ versus $E$ curves are determined by application of actinic light for longer time periods (15 to $60 \mathrm{~min}$ ), and the photosynthetic apparatus of the sample will, therefore, exhibit adaptation to the applied light conditions, e.g. by changes in the effective absorption cross-section of PSII (Kolber \& Falkowski 1993, Falkowski \& Raven 1997). So-called Rapid Light Curves (RLC) can be obtained from $\phi_{\mathrm{p}}$ measurements (and subsequent ETR calculations) after short-term (10 to 20 s) sample illumination with increasing levels of actinic light (White \& Critchley 1998). Such RLCs provide a snap shot of the current status of light adaptation to the ambient light conditions (Schreiber et al. 1997, Ralph et al. 1999). RLCs can be recorded over a short time period (1 to $2 \mathrm{~min}$ ), while, e.g. the xanthophyll cycle for down regulation of photosynthesis, is switched on or off over a time scale of 5 to $30 \mathrm{~min}$ (Ralph et al. 1999).

Fluorescence measurements. A waterproof pulseamplitude-modulated fluorometer (Diving-PAM, Walz, Germany) was used for assessing the effective quantum yield of charge separation in PSII, $\phi_{\mathrm{p}}$, either in situ under ambient light conditions or during the measurement of light curves (by application of defined actinic light levels via the measuring fiber cable of the instrument). In contrast to earlier instruments, our DIVING-PAM was modified to use a blue LED (450 nm emission maximum) for generating weak, non-actinic, microsecond pulses of measuring light $\left(<0.5 \mu \mathrm{mol}\right.$ photons $\left.\mathrm{m}^{-2} \mathrm{~s}^{-1}\right)$. The use of blue measur- ing light has previously been shown to increase the sensitivity of the measurement when studying microalgae (Schreiber 1994).

The internal halogen lamp (20 W) of the Diving-PAM provided actinic light saturation pulses. The irradiance ( $\mu \mathrm{mol}$ photons $\mathrm{m}^{-2} \mathrm{~s}^{-1}$ ) for different actinic light settings of the fluorometer was measured at the output of the immersed $8 \mathrm{~mm}$ fiber cable with a LiCor LI-192SA underwater quantum irradiance sensor. The DivingPAM is equipped with a calibrated irradiance sensor. However, no detailed information about its lightcollecting properties or spectral characteristics is available. The irradiance sensor of the Diving-PAM was therefore calibrated against the LiCor underwater quantum irradiance sensor prior to field experiments. Generally, both irradiance sensors were in good agreement, and we used both for quantifying in situ irradiance.

RLCs were measured by applying a sequence of increasing actinic irradiance in 9 discrete increments. Each period of actinic light lasted for $10 \mathrm{~s}$ before a saturation pulse of white light $(0.6$ to $0.8 \mathrm{~s}$ at $\sim 5000 \mu \mathrm{mol}$ photons $\mathrm{m}^{-2} \mathrm{~s}^{-1}$ ) was applied to determine $\phi_{\mathrm{p}}$. Light curves (LC) were also measured with longer periods (3 min) of actinic illumination at each step, which allowed the photosynthetic apparatus to partially adapt to the increasing irradiance. Relative ETRs in RLCs and LCs were calculated as the product of $\phi_{\mathrm{p}}$ and incident downwelling irradiance, $E_{\mathrm{d}}(\mathrm{PAR})$.

The Diving-PAM was operated by a SCUBA diver as a stand-alone instrument for frequent measurements of PSII quantum yield at the water-ice interface. For such measurements, the fiber-optic cable of the instrument was directed at the object of interest with one hand and short-term measurements were initiated by operating the instrument with the other hand. Laboratory tests showed that these fluorescence measurements represent the dynamic fluorescence response of the lowermost $\sim 10 \mathrm{~mm}$ of the sea ice (data not shown).

For measurements of light curves, the Diving-PAM was mounted on the tripod described above, and controlled from the ice surface by the WIN-CONTROL software (Walz $\mathrm{GmbH}$ ) running on a portable Personal Computer, which was connected to the fluorometer via a $50 \mathrm{~m}$ long underwater cable. For such online measurements, the internal battery of the Diving-PAM was backed-up by two $12 \mathrm{~V}$ batteries also connected to the fluorometer via the underwater cable. The extra batteries prolonged the in situ operation time of the fluorometer in the cold water, when used for prolonged LC series. The fiber cable of the Diving-PAM was mounted on the motorized positioning unit, while the irradiance sensor was mounted horizontally on the tripod facing upward to the ice surface. After the tripod 
was positioned by a SCUBA diver, the tip of the fiber cable, which was mounted in a black PVC holder to screen out ambient light, was moved carefully towards the surface by the motor-driven spindle of the tripod. For measurements on macroalgae, the special leaf clip provided with the Diving-PAM was used to fix the instrument fiber cable to the thallus. When measuring on benthic micro- and macroalgae, 5 to 10 min of adaptation to dark conditions was allowed prior to measurements.

During measurements at the water-ice interface it was not possible to fully darken the ice svolume monitored by the fiber cable due to diffuse downwelling light propagating through the ice. Consequently, we could not determine fluorescence under fully darkadapted conditions, $F_{0}$. Therefore, the first yield measurement (i.e. the first data point on the LCs) relates to the ambient low irradiance, to which the subsequent actinic light levels applied during the measurement were added. $F_{0}$ values determined by measurements on dark-adapted intact ice samples brought to the surface showed that in situ $F$ values measured under the ice at ambient low irradiance underestimated true $F_{0}$ values by 5 to $10 \%$ (Rysgaard et al. 2001).

Curve fitting of LCs. Measured LCs of photosynthesis $P$ in terms of $\mathrm{O}_{2}$ production or ETR versus irradiance $E$ were fitted by the function (Platt et al. 1980):

$$
P=\mathrm{P}_{\mathrm{s}}\left[1-\exp \left(-\alpha E / \mathrm{P}_{\mathrm{s}}\right)\right] \exp \left(-\beta E / \mathrm{P}_{\mathrm{s}}\right)
$$

where $P_{s}$ is a scaling parameter defined as the maximal potential oxygen production or ETR in the absence of photoinhibition, $\alpha$ is the initial slope of the $\mathrm{LC}$, and $\beta$ is the slope of the LC beyond the onset of photoinhibition. The maximal rate at light saturation $P_{\mathrm{m}}$ can be derived as (Harrison \& Platt 1986):

$$
P_{\mathrm{m}}=\mathrm{P}_{\mathrm{s}}[\alpha /(\alpha+\beta)][\beta /(\alpha+\beta)]^{\beta / \alpha}
$$

In the absence of photoinhibition ( $\beta=0)$, Eq. (4) simplifies to:

$$
P=P_{\mathrm{m}}\left[1-\exp \left(-\alpha \mathrm{E} / P_{\mathrm{m}}\right)\right]
$$

This is identical to a mathematical formulation of LCs originally proposed by Webb et al. (1974), which is also analogous to a formulation of photon capture by photosystems based on target theory (Falkowski \& Raven 1997).

When fitting net photosynthesis curves we used Eqs (4) \& (6) modified with an oxygen consumption term. By use of Eqs (4) to (6) the index of light adaptation (i.e. the irradiance at onset of saturation) $E_{\mathrm{k}}$ was calculated as $E_{\mathrm{k}}=P_{\mathrm{m}} / \alpha$. All curve fits were done with a non-linear Levenberg-Marquardt regression algorithm (Origin 6.0, Microcal Software Inc., Northampton, MA).

\section{RESULTS AND DISCUSSION}

\section{Irradiance regime under ice}

Irradiance under the ice cover was in the range of 2 to $30 \mu \mathrm{mol}$ photons $\mathrm{m}^{-2} \mathrm{~s}^{-1}$. The presence of a hole in the ice resulted in a cone of locally increased irradiance under the ice that decreased laterally to ambient levels over the first 3 to $6 \mathrm{~m}$ from the ice hole. In shallow waters ( $<15$ to $20 \mathrm{~m}$ ) a spot of higher-than-ambient irradiance at the sea floor directly below ice holes could also be observed. This local increase in irradiance significantly stimulated photosynthesis of both planktonic and surface associated algae (data not shown). We took advantage of this effect for measuring RLCs of the photosynthetic electron transport activity of the ice algae at different positions relative to the ice hole, corresponding to ice algae with different histories of irradiance exposure (see below). Our irradiance measurements at the water-ice interface probably underestimate the light availability within the layer of ice algae at the interface. A better estimation of available light would require fine-scale in situ measurements of scalar irradiance within the light-scattering matrix of microalgae and ice (see also Rysgaard et al. 2001).

\section{Sea ice microalgae}

Microscopy of diver-collected sea ice samples revealed a microalgal community dominated by large diatoms. The distribution of sea ice microalgae appeared very patchy at scales from a few millimeters to several meters, as judged from numerous fluorescence and yield measurements under the ice, systematically covering scales from centimeters to $\sim 0.5 \mathrm{~km}$ (Rysgaard et al. 2001). Furthermore, the underside of the ice exhibited large temporal variations in topography and structure ranging from a solid and flat appearance to a loose 10 to $20 \mathrm{~cm}$ thick 'crunchy' structure and vice versa within time scales of 1 to $2 \mathrm{~d}$. The water-ice interface represents an extremely heterogeneous habitat in both time and space, which is largely determined by heterogeneous light fields, and fluctuating temperature and salinity gradients (Trodahl et al. 1989, Perowich \& Gow 1991, Eicken 1992). This imposes great difficulties for estimating the magnitude of sea ice productivity. Here we only show selected data from areas of ice with a relatively high density of ice algae, as judged from the chlorophyll fluorescence signals.

In situ oxygen measurements at the water-ice interface demonstrated a net flux of oxygen from the sea ice to the surrounding seawater (Fig. 2A). Oxygen was produced by microalgae within a thin layer of porous 
sea ice under an ambient irradiance of 2 to $5 \mu \mathrm{mol}$ photons $\mathrm{m}^{-2} \mathrm{~s}^{-1}$. This demonstrates active photosynthesis by sea ice microalgae apparently well adapted to low irradiance. The thickness of the active layer was, however, highly variable. When penetrating through the loose layer into the solid ice matrix a sharp decrease in oxygen was observed (Fig. 2A), mainly due to a blocking of the diffusive oxygen supply to the sensor by solid ice. We also observed that ice formation leads to bubble formation and expulsion of gases to the surrounding water, while the solid ice matrix itself
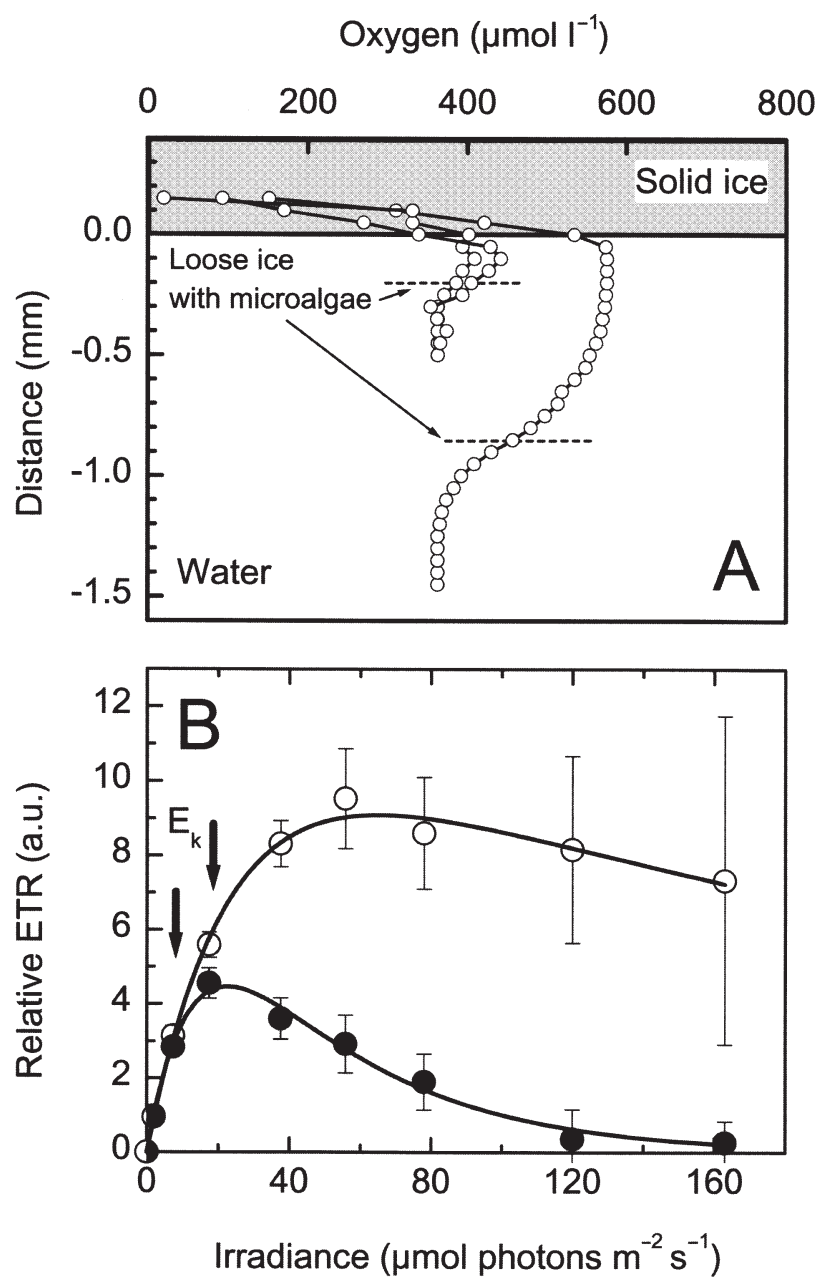

Fig. 2. (A) Microprofiles of oxygen measured in situ with a lander instrument at the water-ice interface (water depth $1.8 \mathrm{~m}, E_{\mathrm{d}}=2$ to $5 \mu \mathrm{mol}$ photons $\mathrm{m}^{-2} \mathrm{~s}^{-1}$ ). (B) Relative (ETR) versus irradiance measured in situ as rapid light curves at the ice-water interface with a lander instrument at the edge $(\mathrm{O})$ and $10 \mathrm{~m}(\mathbf{)})$ distance from an ice hole. Ambient irradiance was 75 and $15 \mu \mathrm{mol}$ photons $\mathrm{m}^{-2} \mathrm{~s}^{-1}$ respectively. Symbols with error bars represent the mean $( \pm \mathrm{SD})$ of 3 to 4 measurements. Solid lines represent non-linear curve fits of Eq. (4) to the datasets $\left(r^{2}>0.995\right.$ and 0.985 respectively). The index of light adaptation $E_{\mathrm{k}}$ was calculated to 18.5 and $7.9 \mu \mathrm{mol}$ photons $\mathrm{m}^{-2} \mathrm{~s}^{-1}$ respectively (arrows on graph) becomes oxygen depleted (data not shown). Such phenomena complicate the interpretation of oxygen microprofiles at the water-ice interface, the structure of which is in a dynamic equilibrium governed by the temperature and salinity microenvironments. A more detailed discussion of the physico-chemical properties and the dynamics of dissolved gases in sea ice are, however, outside the scope of this study and will be presented elsewhere (Glud et al. unpubl.).

Due to the above-mentioned complexity of the water-ice interface, we did not attempt to quantify photosynthesis by calculations of oxygen fluxes from measured microprofiles, or to quantify photosynthesis versus irradiance curves from our measurements. Calculations, assuming 1-dimensional diffusion geometry, were previously performed on in situ oxygen profiles measured on dense Antarctic sea ice communities as a function of irradiance (McMinn et al. 2000). Based on our in situ experiments, we find the application of such an approach to calculate oxygen fluxes at the water-ice interface problematic. Besides the obvious problems of applying a one-dimensional description of solute exchange at a heterogeneous interface undergoing dynamic changes, another prominent difficulty is to choose the correct mass transfer coefficient for flux calculations. We do not know, for example, to what extent solute exchange at the water-ice interface, which is a permeable porous structure, is governed by both diffusion and advection, or to what extent small spatiotemporal temperature and salinity variations affect mass transfer.

Fast in situ measurements of active fluorescence as a function of irradiance (RLC) enabled us to study adaptation of sea ice microalgae to different irradiance regimes around an ice hole (Fig. 2B). Measurements on ice algae, growing under ambient light conditions far from the hole, showed adaptation to low irradiance with a photoadaptive index $E_{\mathrm{k}}$ of $7.9 \mu \mathrm{mol}$ photons $\mathrm{m}^{-2}$ $\mathrm{s}^{-1}$ and pronounced photoinhibition $(>20 \mu \mathrm{mol}$ photons $\mathrm{m}^{-2} \mathrm{~s}^{-1}$ ). Close to the ice hole, ice algae were exposed to much higher irradiance and RLC measurements exhibited a higher onset of photosynthesis saturation (i.e. $E_{\mathrm{k}}=18.5 \mu \mathrm{mol}$ photons $\mathrm{m}^{-2} \mathrm{~s}^{-1}$ ) and less severe photoinhibition at higher irradiance. Cota (1985) reviewed $E_{\mathrm{k}}$ values of ice algae and found a typical range of 2 to $10 \mu \mathrm{mol}$ photons $\mathrm{m}^{-2} \mathrm{~s}^{-1}$. Furthermore, the same study showed that shade-adapted, high-Arctic ice algae exhibited maximal photosynthesis at maximal ambient irradiance levels and were inhibited at higher irradiances. An inherent uncertainty in our data and most other reported data is, however, that the ambient irradiance inside the light-scattering layer and absorbing layer of sea ice microalgae has not been quantified. Hence, available irradiance is estimated from downwelling irradiance measured immediately 

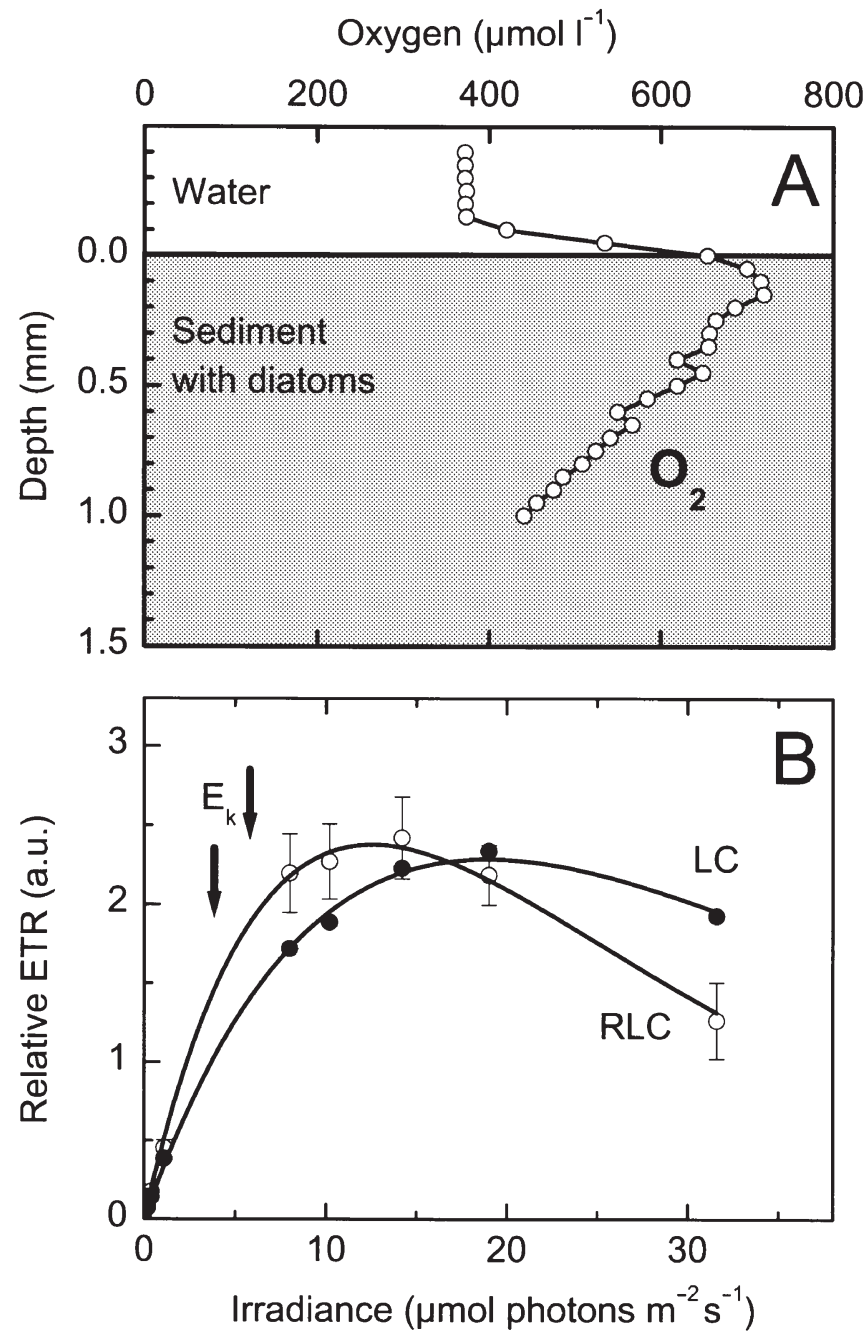

Fig. 3. (A) Oxygen microprofile in benthic diatom biofilm. (B) Light curve $(\mathrm{LC}, \mathbf{0})$ and rapid light curve (RLC, $\mathrm{O}$; mean $\pm \mathrm{SD}, \mathrm{n}=4$ ) of relative ETR versus irradiance in the biofilm. Both oxygen profiles and light curves were measured in situ at the sediment-water interface at $10 \mathrm{~m}$ water depth with a lander instrument placed directly below an ice hole. Ambient irradiance was 20 to $30 \mu \mathrm{mol}$ photons $\mathrm{m}^{-2} \mathrm{~s}^{-1}$. Solid lines in (B) represent non-linear curve fits of Eq. (4) to the datasets $\left(\mathrm{r}^{2}>0.998\right)$. The index of light adaptation $E_{\mathrm{k}}$ was calculated to $6.9 \mu \mathrm{mol}$ photons $\mathrm{m}^{-2} \mathrm{~s}^{-1}$ (LC) and $4.6 \mu \mathrm{mol}$ photons $\mathrm{m}^{-2} \mathrm{~s}^{-1}$ (RLC) (arrows on graph)

below the water-ice interface. With highly scattering media this results in an underestimation of available irradiance, as previously shown in sediments (Kühl et al. 1994). How large this underestimation is awaits detailed measurements of scalar irradiance in the matrix of sea ice and microalgae.

Our data indicate that higher irradiance regimes seem to promote acclimation and adaptation of ice algae towards the higher light availability. This is consistent with earlier findings from Antarctic ice algae. Robinson et al. $(1995,1998)$ reported $E_{\mathrm{k}}$ values of 3.7 to
$12.6 \mu \mathrm{mol}$ photons $\mathrm{m}^{-2} \mathrm{~s}^{-1}$ and showed acclimation of ice algae to the seasonal increase in ambient irradiance. Frequent in situ measurements of active fluorescence in Young Sound also showed acclimation of ice algae to the seasonal variation in light availability (Rysgaard et al. 2001). Robinson et al. (1998) reported laboratory measurements of quantum yields of PSII ranging from 0.3 to 0.5 in ice algae, while our in situ data showed PSII quantum yields of 0.3 to 0.65 for ice algae.

\section{Benthic microalgae}

A survey with digital underwater photography of the shallow parts of the sea floor in the ice-covered Young Sound showed the presence of dark-brown patches covering $\sim 30$ to $60 \%$ of the sediment surface at $\sim 5$ to $35 \mathrm{~m}$ water depth (data not shown). The brown patches were composed of dense biofilms harboring a diverse community of pennate diatoms. In situ measurements of oxygen at $10 \mathrm{~m}$ water depth directly below the ice hole demonstrated net oxygen production under the prevailing irradiance of $\sim 20$ to $30 \mu \mathrm{mol}$ photons $\mathrm{m}^{-2} \mathrm{~s}^{-1}$ (Fig. 3A). The microprofiles showed the presence of a 0.1 to $0.2 \mathrm{~mm}$ thick DBL. Assuming a one-dimensional diffusion geometry and an oxygen diffusion coefficient in the bottom water of $\mathrm{D}_{0}=1.02 \times 10^{-5} \mathrm{~cm}^{2} \mathrm{~s}^{-1}$, at the in situ salinity $(31 \%)$ and temperature $\left(-0.5^{\circ} \mathrm{C}\right)$, we calculated a net photosynthesis of $P_{\mathrm{n}}=100 \mathrm{mmol} \mathrm{O}_{2} \mathrm{~m}^{-2} \mathrm{~d}^{-1}$. This is a surprisingly high rate of production given the low incident irradiance, and highlights that benthic microalgae can contribute a major part of the primary production in shallow arctic waters (Matheke \& Horner 1974, Horner \& Schrader 1982). However, the productivity of benthic microalgae in ice-covered systems is under-explored as compared to the more intensively studied sea ice microalgae.

Active fluorescence measurements on the diatom biofilms showed a PSII photon yield ranging from 0.40 to 0.65 under natural irradiance regimes (data not shown), which is in line with published values for intertidal diatoms (e.g. Hartig et al. 1998). In situ measurements of RLCs (i.e. of relative ETR versus irradiance) exhibited a low photoadaptive index, $E_{\mathrm{k}}$, of $4.6 \mu \mathrm{mol}$ photons $\mathrm{m}^{-2} \mathrm{~s}^{-1}$ and inhibition at $>10$ to $15 \mu \mathrm{mol}$ photons $\mathrm{m}^{-2} \mathrm{~s}^{-1}$ (Fig. 3B), showing that the benthic diatoms were adapted to the low ambient irradiance. However, when measuring LCs at the same spot but with longer exposure times, the benthic diatoms exhibited photoacclimation towards higher irradiance as judged from a higher $E_{\mathrm{k}}$ of $6.9 \mu \mathrm{mol}$ photons $\mathrm{m}^{-2} \mathrm{~s}^{-1}$ and a less pronounced inhibition above the saturation irradiance (Fig. 3B). Palmisano et al. (1985) and Rivkin \& Putt (1987) reported a photoadaptive index of benthic 
diatom communities of 11 and $6 \mu \mathrm{mol}$ photons $\mathrm{m}^{-2} \mathrm{~s}^{-1}$ respectively. Benthic microalgae from ice covered McMurdo Sound, Antarctica, exhibited a photoadaptive index of 1.3 to $4.5 \mu \mathrm{mol}$ photons $\mathrm{m}^{-2} \mathrm{~s}^{-1}$ and were shown to harvest available irradiance very efficiently due to strong pigment packaging and complementation between spectral absorption of diatoms and available spectral irradiance at the sea floor (Robinson et al. 1995). We did not investigate the pigmentation of benthic diatoms or spectral characteristics of the light field, but the dark-brown and almost opaque appearance of the diatom biofilm patches on the sediment indicated strong pigmentation and efficient light harvesting of the diatoms.
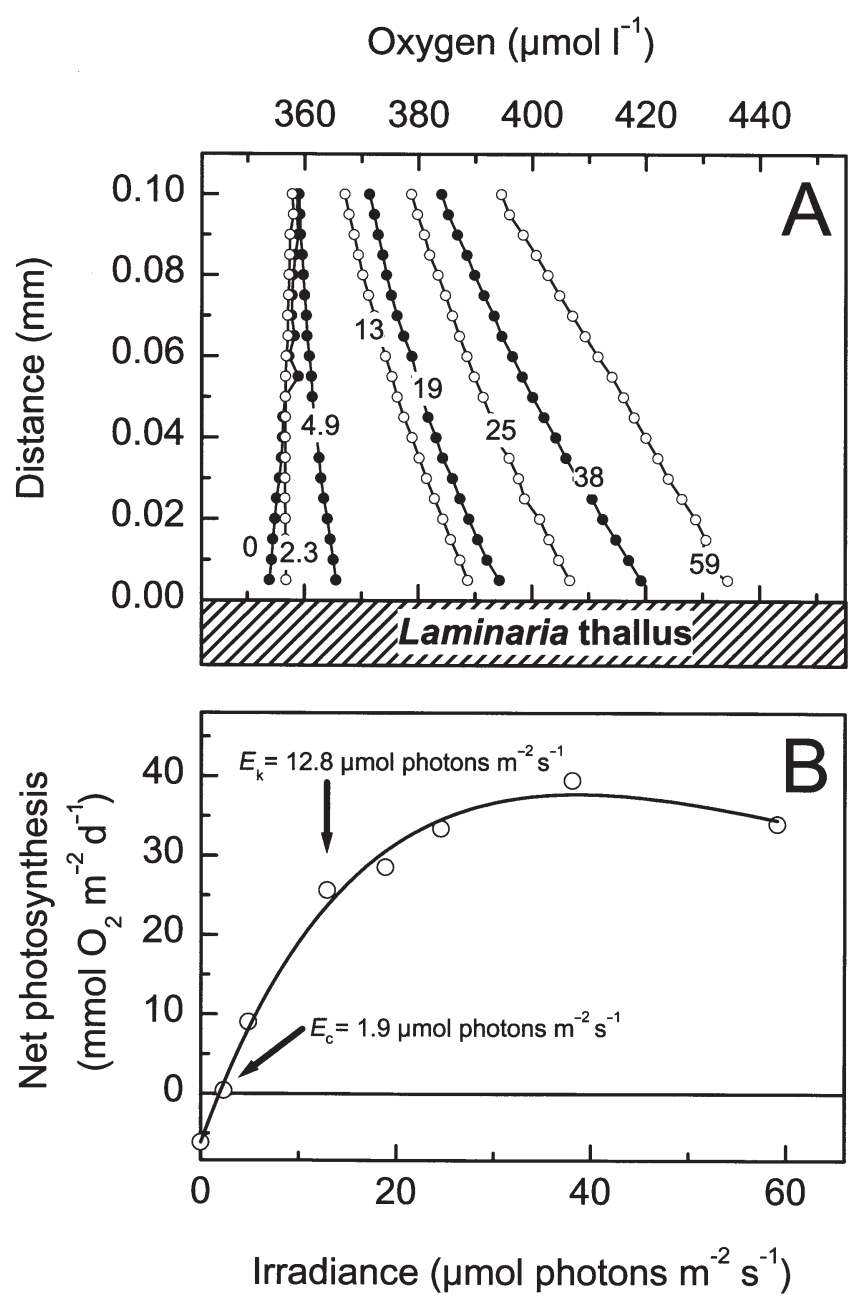

Fig. 4. Oxygen microprofiles (A) and net oxygen production versus irradiance curves (B) measured in the laboratory $\left(0^{\circ} \mathrm{C}\right)$ on the brown alga Laminaria saccharina. Numbers in (A) indicate experimental irradiance in $\mu \mathrm{mol}$ photons $\mathrm{m}^{-2} \mathrm{~s}^{-1}$. Solid line in (B) represents a non-linear curve fit of Eq. (4) (with an oxygen consumption term), to the $P_{\mathrm{n}}$ versus $E$ data $\left(\mathrm{r}^{2}>0.997\right)$. Arrows indicate the compensation irradiance $E_{\mathrm{c}}$ and the index of light adaptation $E_{\mathrm{k}}$

\section{Brown macroalgae}

Dense beds of macroalgae were found at $\sim 0.5$ to $15 \mathrm{~m}$ depth in Young Sound, and the photosynthetic characteristics of dominant species from $\sim 10 \mathrm{~m}$ depth were investigated both in the laboratory and in situ.

Macroalgal biomass was dominated by Laminaria saccharina, Fucus evanescens, and Desmarestia aculeata. Microsensor measurements of oxygen concentration gradients towards the thallus of $L$. saccharina in dark and at increasing irradiance allowed calculations of net oxygen fluxes (Fig. 4A). The resulting net photosynthesis versus irradiance curve showed a compensation irradiance $E_{\mathrm{c}}$ of $1.9 \mu \mathrm{mol}$ photons $\mathrm{m}^{-2} \mathrm{~s}^{-1}$, and a photoadaptive index $E_{\mathrm{k}}$ of $12.8 \mu \mathrm{mol}$ photons $\mathrm{m}^{-2} \mathrm{~s}^{-1}$ (Fig. 4B). Compensation irradiances of L. saccharina $\left(2.0 \mu \mathrm{mol}\right.$ photons $\left.\mathrm{m}^{-2} \mathrm{~s}^{-1}\right)$, D. aculeata $(4.1 \mu \mathrm{mol}$ photons $\left.\mathrm{m}^{-2} \mathrm{~s}^{-1}\right)$ and $F$. evanescens $\left(8.5 \mu \mathrm{mol}\right.$ photons $\left.\mathrm{m}^{-2} \mathrm{~s}^{-1}\right)$ were measured in a parallel laboratory study of total oxygen exchange (data not shown).

Low light adaptation of the mentioned macroalgae was also evident from measured LCs of ETR versus irradiance (Fig. 5). In situ PSII quantum yields ranged from 0.4 to 0.7 , which is typical for brown macroalgae. As for benthic microalgae, RLCs exhibited saturation at lower irradiances and more pronounced inhibition at higher irradiance (Fig. 5, right panels) than observed for LCs obtained with longer illumination at each level of actinic light (Fig. 5, left panels). During the measurement of the latter type of light curve the macroalgae adapt to a higher irradiance regime, which is also evident by measurements of RLCs just after the LC measurements ended (Fig. 5B,C, right panels). In Desmarestia aculeata we continued to measure RLCs over a longer time interval after ending the LC measurement. These RLCs showed that D. aculeata returned to the initial adaptation to low irradiance within 10 to $15 \mathrm{~min}$. Macroalgae under ice cover are thus able to rapidly adapt to changes in ambient irradiance, and light curves based on longer illumination periods, such as used for measuring photosynthesis versus irradiance curves via oxygen production, may therefore not reflect the photosynthetic capacity under in situ conditions. The mechanisms behind this rapid photoacclimation in macroalgae and whether similar mechanisms occur in benthic and epontic microalgae remain to be studied in more detail.

Photoadaptation and photoinhibition characteristics of Arctic brown algae have been intensively studied by Hanelt \& coworkers with a combination of oxygen production and variable fluorescence methods. A dynamic photoacclimation towards both high levels of PAR and UV radiation was demonstrated among Arctic macroalgae (Hanelt \& Nultsch 1995, Hanelt et al. 1997, Hanelt 1998). Fluorescence measurements based on 


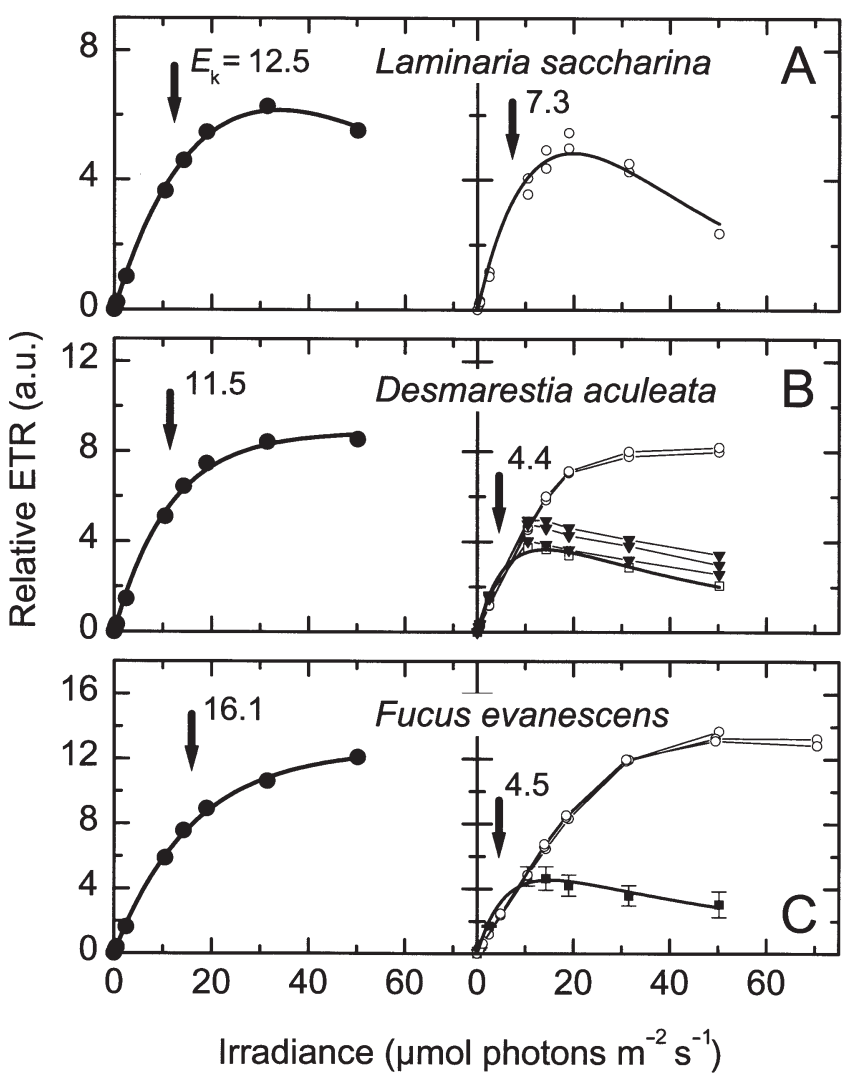

Fig. 5. Light curves (LC, left panels) and rapid light curves (RLC, right panels) of relative ETR versus irradiance measured in situ on 3 different macroalgae: Laminaria saccharina (A), Fucus evanescens (B) and Desmarestia aculeata (C). Thick solid lines through ETR versus irradiance data represent curve fits of Eqs (4) \& (6). All fits had ${ }^{2}>0.988$. Arrows with numbers indicate the index of light adaptation $E_{\mathrm{k}}$. (A) The RLC (O) was measured immediately before the LC (0). (B) The RLC was measured immediately before ( $\square$ ) or immediately after $(\mathrm{O})$ the LC and over the next 10 to $15 \mathrm{~min}(\mathbf{v})$. (C) The RLC (mean \pm standard deviation, $\mathrm{n}=4$ ) was measured immediately before ( $\square)$ or immediately after (O) the LC

the saturation pulse technique were consistent with those of oxygen measurements of photosynthetic efficiency in macroalgae (Hanelt et al. 1995). In our dataset, we also found a good correspondence between LCs measured with oxygen microelectrodes and those LCs measured with the saturation pulse method using longer exposure times for each actinic light level (compare Fig. 4B and left panel in Fig. 5A). Both approaches gave similar photoadaptive indices and showed the same basic shape of the LCs.

Our data on macroalgae show lower $E_{\mathrm{k}}$ values than those reported from other studies in the Arctic (reviewed by Kirst \& Wiencke 1995). In an in situ study of Laminaria solidungula, Dunton \& Jodwalis (1988) thus found an $E_{\mathrm{k}}$ of $\sim 38 \mu \mathrm{mol}$ photons $\mathrm{m}^{-2} \mathrm{~s}^{-1}$ in plants from 6 to $7 \mathrm{~m}$ depth. We investigated macroalgae from
10 m depth, probably adapted to lower ambient irradiance. Rapid acclimation to non-inhibiting irradiance allows macroalgae to optimize photosynthetic performance and we would therefore expect differences in $E_{\mathrm{k}}$ between algae exhibiting different light regimes, e.g. as a function of water depth or snow cover on the sea ice. We did not undertake in situ measurements on macroalgae from different water depths, but such studies can now easily be undertaken with the methods presented in this paper.

\section{Coralline red algae}

Coralline red algae (mainly Phymatolithon foecundum) formed bright pink crusts on stones at the sea floor at water depths of $\sim 15$ to $40 \mathrm{~m}$. These algae exhibited an effective adaptation to low irradiance (Fig. 6). Oxygen microprofiles measured towards the smooth, calcified surface of the red algae showed a very thin DBL of only 100 to $150 \mu \mathrm{m}$ (Fig. 6A) and rather low rates of oxygen consumption and production. From oxygen profiles measured in the dark and at increasing irradiance, a complete net photosynthesis versus irradiance curve could be generated, which showed a low compensation irradiance $E_{\mathrm{c}}$ of $1.6 \mu \mathrm{mol}$ photons $\mathrm{m}^{-2}$ $\mathrm{s}^{-1}$, and a saturation irradiance $E_{\mathrm{k}}$ of $17 \mu \mathrm{mol}$ photons $\mathrm{m}^{-2} \mathrm{~s}^{-1}$ (Fig. 6B). No photoinhibition was observed up to $130 \mu \mathrm{mol}$ photons $\mathrm{m}^{-2} \mathrm{~s}^{-1}$. In situ measurements of RLC's exhibited only slight photoinhibition and an $E_{\mathrm{k}}=11 \mu \mathrm{mol}$ photons $\mathrm{m}^{-2} \mathrm{~s}^{-1}$ (Fig. 6C).

Photosynthetic performance of coralline red algae in polar waters is still literally unstudied (Johansen 1981, Steneck 1986), and the microenvironmental controls of productivity are unknown. Productivity of coralline algae was studied in sub-Arctic waters (Adey 1973), and Kaspar (1992) used oxygen microsensors to study the coralline Lithothamnion sp. from temperate Danish waters. To our knowledge, we present the first dataset on the oxygen microenvironment and net photosynthesis of Arctic coralline red algae. In his microsensor study of corallines from temperate waters, Kaspar (1992) applied a similar DBL thickness, but the shallow water species he investigated exhibited both higher compensation irradiance $\left(10 \mu \mathrm{mol}\right.$ photons $\left.\mathrm{m}^{-2} \mathrm{~s}^{-1}\right)$ and photoadaptive index (50 to $100 \mu \mathrm{mol}$ photons $\mathrm{m}^{-2} \mathrm{~s}^{-1}$ ), in agreement with other studies on corallines in subarctic waters (Adey 1973). The low rates of photosynthesis and low in situ irradiance observed in our study indicate a minor contribution of coralline algae to overall primary production under ice cover. More accurate estimates of coralline productivity would require, however, measurements of species abundance and photosynthetic performance as a function of depth together with seasonal mapping of available irradiance at the sea floor. 


\section{Conclusions}

Hitherto, the physico-chemical microenvironment in situ and its importance for the productivity of surfaceassociated phototrophs in ice-covered regions have been poorly characterized. This study thus presents new data on the oxygen conditions both at the sediment-water and the water-ice interface. To our knowledge, we present the first in situ measurements of oxygen dynamics and relative ETR in sediments, macroalgae and communities of sea ice microalgae in the Arctic. McMinn et al. (2000) presents in situ oxygen data measured on Antarctic Sea ice microalgae.
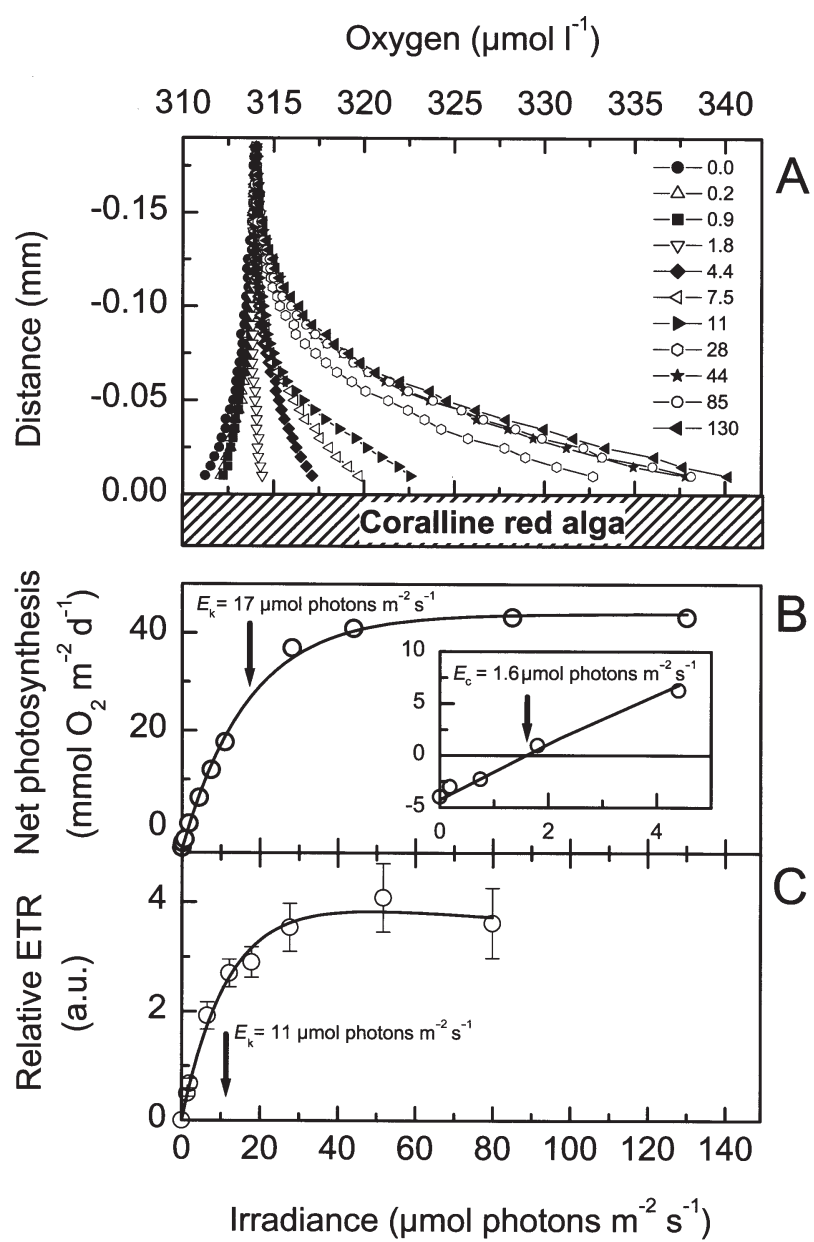

Fig. 6. Oxygen microprofiles (A) and net oxygen production versus irradiance curves (B) measured in the laboratory $\left(5^{\circ} \mathrm{C}\right)$ on the coralline red alga Phymatolithon foecundum. (C) In situ measurements of RLCs on 7 stones covered by coralline red algae (symbols with error bars indicate the mean $\pm \mathrm{SD}$ ). Solid line in Panel B represents a non-linear curve fit of Eq. (6) (with an oxygen consumption term), to the $P_{\mathrm{n}}$ versus $E$ data $\left(\mathrm{r}^{2}>0.997\right)$. Inset shows a close-up view of the $P_{\mathrm{n}}$ versus $E$ curve at low irradiances. Solid line in Panel C represents a non-linear curve fit of Eq. (4) to the relative ETR versus $E$ data $\left(\mathrm{r}^{2}>0.989\right)$. Arrows indicate the compensation irradiance, $E_{\mathrm{C},}$ and the index of light adaptation, $E_{\mathrm{k}}$
Our measurements revealed the presence of a Diffusive Boundary Larger (DBL), which impedes mass transfer of solutes and dissolved gases at various interfaces below the sea ice. The importance of the DBL has been demonstrated in several studies of benthic phototrophs (e.g. Jørgensen \& Revsbech 1985, Kaspar 1992, Koch 1994, Jørgensen in press). Similar conclusions can probably be drawn for the role of the DBL for benthic photosynthesis in ice-covered regions, but detailed studies still need to be undertaken.

Furthermore, it is now a challenging task to apply microsensor techniques to study photosynthesis and mass transfer at the water-ice interface in order to increase our understanding of this complex and highly dynamic microbial habitat. Mass transfer at the ice-water interface is complex due to the inherently heterogeneous and porous structure of the interface and due to complicated interactions between structure, temperature and salinity fluctuations (Weeks \& Ackley 1982, Perowich \& Gow 1991, Eicken 1992). Thus it remains to be shown whether mass transfer can be satisfactorily described by diffusional exchange or whether a combination of advection and diffusion governs mass transfer. Such information is essential to better evaluate and optimize traditional methods which have been used for photosynthesis studies below sea ice. A weakness of the microsensor approach is, however, the practical limitation to relatively few point measurements in situ, which cannot fully reveal the inherent 3-dimensional heterogeneity present at the sediment-water and the water-ice interface, and which therefore makes extrapolation to larger scales problematic.

Active fluorescence measurements with new in situ instruments provide a rapid and simple analysis of the light-adaptation status of phototrophic algae. Our in situ data, obtained by a combination of RLC and LC measurements, demonstrated a fast and reversible acclimation of algae to varying irradiance levels under sea ice. The fast acclimation would not have been observed by use of traditional in situ approaches, which rely on long incubation times. Another important advantage of the Diving-PAM instrument (and other in situ fluorometers) is the ability to conduct numerous measurements in situ within a dense measuring grid and, thereby, map the heterogeneous distribution and activity of phototrophs at various scales. Such measurements can help alleviate problems due to undersampling (Wiggert et al. 1994) when estimating primary productivity on larger scales from point measurements. For example, the patchy distribution of sea ice microalgae was mapped in situ at scales ranging from a few centimeters to $0.5 \mathrm{~km}$ (Rysgaard et al. 2001). 
However, some optimization of the Diving-PAM fluorometer still needs to be done. Adjusting the voltage of an internal halogen lamp in the instrument generates different actinic light levels at the output of the fiber cable. This causes shifts in the spectral composition of the actinic light as the color temperature increases. We did not account for these effects in our study. Furthermore, when used at moderate temperature or during laboratory experiments, the heating of the halogen lamp can result in shifting of irradiance over time. Internal heating also limits the period of actinic light to $3 \mathrm{~min}$, when using the internal light source of the PAM fluorometer. The use of an LED array as internal actinic light source could alleviate the above-mentioned problems.

When fluorescence studies are combined with oxygen microsensor techniques, it is especially important to match the resolution of the techniques, in order to make a relevant comparison and to avoid artifacts, e.g. due to obstruction of the local flow regime at the measuring spot by the large fiber. Besides the $8 \mathrm{~mm}$ fiber cable, a $1 \mathrm{~mm}$ fiber can also be used with the Diving-PAM, and this would allow patchiness to be measured on a millimeter scale. In situ instruments for microscale chlorophyll fluorescence need to be developed. Microscale fluorescence measurements at $<100 \mu \mathrm{m}$ spatial resolution have already been made in leaves (Schreiber et al. 1996), ascidians (M. Kühl unpubl. data), sediments and biofilms (Kühl \& Fenchel 2000), by combined measurements with fiber-optic microprobes and oxygen microsensors.

Theoretically, an absolute measure of photosynthesis rate is possible with the fluorescence techniques, but this would require detailed information about factors such as the absorption cross-section of PSII in microalgae within the sampling volume, which is difficult to obtain in most experiments with natural samples. However, instruments such as the recently developed underwater fast-repetition-rate fluorometer (Gorbunov et al. 2000), which are based on the socalled pump and probe method, may allow such measurements. In any case, a prerequisite for more quantitative use of active fluorescence techniques for in situ studies in aquatic ecology is a careful and detailed intercalibration with oxygen exchange or ${ }^{14} \mathrm{C}$-based techniques (e.g. Hartig et al. 1998, Barranguet \& Kromkamp 2000). Such an intercalibration for our measurements is, however, outside the scope of the present paper and will be described elsewhere (Glud et al. unpubl. data). Here we have demonstrated the use of new instrumentation for photosynthesis studies, which allows in situ studies of light adaptation and primary production under ice cover at an unprecedented level of resolution.
Acknowledgements. This study was funded by the Danish Natural Science Research Council (Contracts 9700549, 9701839, 97000224, 9802967) and the Commission for Scientific Research in Greenland (Contract 602-53). The study was conducted as part of the project 'Changes in Arctic Marine Production' (CAMP). We acknowledge the help and jolly atmosphere due to the team on the June 1999 expedition to 'Kystens Perle'. J.W.H. Posemanden is thanked for detailed logistic planning and for providing essential nutrients in crucial moments. Especially, Thomas V. Rasmussen is thanked for his tireless help with logistics and diving operations. The Danish military division 'Sirius' is gratefully acknowledged for their hospitality and essential help during the fieldwork. Anni Glud and Unisense A/S are thanked for providing microsensors, technical assistance and measuring equipment for the study. Rolf Gademann and Walz GmbH are thanked for their development of the blue LED option and the underwater cable control of the Diving-PAM.

\section{LITERATURE CITED}

Adey WH (1973) Temperature control of reproduction and productivity in subarctic coralline alga. Phycologia 12: $111-118$

Andersen OGN (1977) Primary production associated with sea ice at Godhavn, Disko, West Greenland. Ophelia 16: 205-220

Barber J, Malkin S, Telfer A (1989) The origin of chlorophyll fluorescence in vivo and its quenching by the photosystem II reaction centre. Philos Trans R Soc Lond B Biol Sci 323: 227-239

Barranguet C, Kromkamp J (2000) Estimating production rates from photosynthetic electron transport in estuarine microphytobenthos. Mar Ecol Prog Ser 204:39-52

Beer S, Björk M (2000) Measuring rates of photosynthesis of two tropical seagrasses by pulse amplitude modulated (PAM) fluorometry. Aquat Bot 66:69-76

Beer S, Ilan M, Eshel A, Weil A, Brickner I (1998) Use of pulse amplitude modulated (PAM) fluorometry for in situ measurements of photosynthesis in two Red Sea faviid corals. Mar Biol 131:607-612

Bolhar-Nordenkampf HR, Long SP, Baker NR, Öquist G, Schreiber U, Lechner EG (1989) Chlorophyll fluorescence as a probe of the photosynthetic competence of leaves in the field: a review of current instrumentation. Funct Ecol 3:497-514

Booth JA (1984) The epontic algal community of the ice edge zone and its significance to the Davis Strait ecosystem. Arctic 37:234-243

Broecker WS, Peng TH (1974) Gas exchange rates between air and sea. Tellus 26:21-35

Cota GF (1985) Photoadaptation of high Arctic ice algae. Nature 315:219-222

Dunton KH, Jodwalis CM (1988) Photosynthetic performance of Laminaria solidungdula measured in situ in the Alaskan high Arctic. Mar Biol 98:277-285

Eicken H (1992) The role of sea ice in structuring Antarctic ecosystems. Polar Biol. 12:3-13

Falkowski PG, Kolber Z (1993) Estimation of phytoplankton photosynthesis by active fluorescence. ICES Mar Sci Symp 197:92-103

Falkowski PG, Raven JA (1997) Aquatic photosynthesis. Blackwell Science, Malden, MA

Falkowski PG, Wyman K, Ley AC, Mauzerall DC (1986) Relationship of steady-state photosynthesis to fluorescence in eucaryotic microalgae. Biochim Biophys Acta 849:183-192 
Flameling IA, Kromkamp J (1998) Light dependence of quantum yields for PSII charge separation and oxygen evolution in eucaryotic algae. Limnol Oceanogr 43:284-297

Genty B, Briantais JM, Baker NR (1989) The relationship between the quantum yield of photosynthetic electron transport and quenching of chlorophyll fluorescence. Biochim Biophys Acta 990:87-92

Glud RN, Gundersen JK, Ramsing NB (2000a) Electrochemical and optical oxygen microsensors for in situ measurements. In: Buffle J, Horvai G (eds) In situ monitoring of aquatic systems - chemical analysis and speciation. J Wiley, Chichester, p 19-75

Glud RN, Risgaard-Petersen N, Thamdrup B, Fossing H, Rysgaard S (2000b) Benthic carbon mineralisation in a high arctic sound (Young Sound, NE-Greenland). Mar Ecol Prog Ser 206:59-71

Gorbunov MY, Falkowski P, Kolber Z (2000) Measurements of photosynthetic parameters in benthic organisms in situ using a SCUBA-based fast repetition rate fluorometer. Limnol Oceanogr 45:242-245

Hanelt D (1998) Capability of dynamic photoinhibition in Arctic macroalgae is related to their depth distribution. Mar Biol 131:361-369

Hanelt D, Nultsch W (1995) Field studies of photoinhibition show non-correlations between oxygen and fluorescence measurements in the Arctic red alga Palmaria palmata. J Plant Physiol 145:31-38

Hanelt D, Uhrmacher S, Nultsch W (1995) The effect of photoinhibition on photosynthetic oxygen production in the brown alga Dictyota dichotoma. Bot Acta 108:99-105

Hanelt D, Melchersmann B, Wiencke C, Nultsch W (1997) Effects of high light stress on photosynthesis of polar macroalgae in relation to depth distribution. Mar Ecol Prog Ser 149:255-266

Harrison WG, Platt T (1986) Photosynthesis-irradiance relationships in polar and temperate phytoplankton populations. Polar Biol 5:153-164

Hartig P, Wolfstein K, Lippemeier S, Colijn F (1998) Photosynthetic activity of natural microphytobenthos populations measured by fluorescence (PAM) and ${ }^{14} \mathrm{C}$-tracer methods: a comparison. Mar Ecol Prog Ser 166:53-62

Henley WJ (1993) Measurement and interpretation of photosynthetic light-response curves in algae in the context of photoinhibition and diel changes. J Phycol 29:729-739

Hofstraat JW, Peeters JCH, Snel JFH, Geel C (1994) Simple determination of photosynthetic efficiency and photoinhibition of Dunaliella tertiolecta by saturating pulse fluorescence measurements. Mar Ecol Prog Ser 103:187-196

Horner R, Schrader GC (1982) Relative contributions of ice algae, phytoplankton and benthic microalgae to primary production in nearshore regions of the Beaufort Sea. Arctic 35:485-503

Johansen HW (1981) Coralline algae, a first synthesis. CRC Press, Boca Raton

Jørgensen BB (2001) Life in the diffusive boundary layer. In: Boudreau BP, Jørgensen BB (eds) The benthic boundary layer. Oxford University Press, Oxford, p 348-374

Jørgensen BB, Revsbech NP (1985) Diffusive boundary layers and the oxygen uptake of sediments and detritus. Limnol Oceanogr 30:11-21

Kaspar HF (1992) Oxygen conditions on surfaces of coralline red algae. Mar Ecol Prog Ser 81:97-100

Kirst O, Wiencke C (1995) Ecophysiology of polar algae. J Phycol 31:181-199

Koch EW (1994) Hydrodynamics, diffusion-boundary layers and photosynthesis of the seagrasses Thalassia testudinum and Cymodocea nodosa. Mar Biol 118:767-776
Kolber Z, Falkowski PG (1993) Use of fluorescence to estimate phytoplankton photosynthesis in situ. Limnol Oceanogr 38:1646-1665

Krause GH, Weis E (1991) Chlorophyll fluorescence and photosynthesis: the basics. Annu Rev Plant Physiol 42: 313-349

Kühl M, Fenchel T (2000) Bio-optical characteristics and the vertical distribution of photosynthetic pigments and photosynthesis in an artificial cyanobacterial mat. Microb Ecol 40:94-103

Kühl M, Lassen C, Jørgensen BB (1994) Light penetration and light intensity in sandy sediments measured with irradiance and scalar irradiance fiber-optic microprobes. Mar Ecol Prog Ser 105:139-148

Kühl M, Glud RN, Ploug H, Ramsing NB (1996) Microenvironmental control of photosynthesis and photosynthesiscoupled respiration in an epilithic cyanobacterial biofilm. J Phycol 32:799-812

Lassen C, Bebout LE, Paerl HW, Jørgensen BB (1994) Microsensor studies of oxygen and light distribution in the green macroalga Codium fragile. J Phycol 30:381-386

Li YH, Gregory S (1974) Diffusion of ions in seawater and in deep-sea sediments. Geochim Cosmochim Acta 38: 703-714

Matheke GEM, Horner R (1974) Primary productivity of the benthic microalgae in the Chukchi Sea near Barrow, Alaska. J Fish Res Board Can 31:1779-1786

McMinn A, Ashworth C, Ryan KC (2000) In situ net primary productivity of an Antarctic fast ice bottom algal community. Aquat Microb Ecol 21:177-185

Mock T, Gradinger R (1999) Determination of Arctic ice algal production with a new in situ incubation technique. Mar Ecol Prog Ser 177:15-26

Palmisano AC, SooHoo JB, White DC, Smith GA, Stanton GR, Burckle LH (1985) Shade adapted benthic diatoms beneath Antarctic sea ice. J Phycol 21:664-667

Perowich DK, Gow AJ (1991) A statistical description of the microstructure of young sea ice. J Geophys Res 96: 16943-16953

Platt T, Gallegos CL, Harrison WG (1980) Photoinhibition of photosynthesis in natural assemblages of marine phytoplankton. J Mar Res 38:687-701

Ralph PJ, Gademann R, Dennison WC (1998) In situ seagrass photosynthesis measured using a submersible pulseamplitude modulated fluorometer. Mar Biol 132:367-373

Ralph PJ, Gademann R, Larkum AWD, Schreiber U (1999) In situ underwater measurements of photosynthetic activity of coral zooxanthellae and other reef-dwelling dinoflagellate endosymbionts. Mar Ecol Prog Ser 180:139-147

Reimers CE, Glud RN (2000) In situ chemical measurements at the sediment-water interface. In: Varney M (ed) Chemical sensors in oceanography, Gordon and Breach Publishing Group, London, p 249-282

Revsbech NP (1989) An oxygen microelectrode with a guard cathode. Limnol Oceanogr 34:474-478

Rivkin RB, Putt M (1987) Photosynthesis and cell division by Antarctic microalgae: Comparison of benthic, planktonic and ice algae. J Phycol 23:223-229

Robinson DH, Arrigo KR, Iturriaga R, Sullivan CW (1995) Microalgal light-harvesting in extreme low-light environments in McMurdo Sound, Antarctica. J Phycol 31:508-520

Robinson DH, Arrigo KR, Kolber Z, Gosselin M, Sullivan CW (1998) Photophysiological evidence of nutrient limitation of platelet ice algae in McMurdo Sound, Antarctica. J Phycol 34:788-797

Rysgaard S, Thamdrup B, Risgaard-Petersen N, Fossing H, Berg P, Christensen PB, Dalsgaard T (1998) Seasonal car- 
bon and nutrient mineralisation in a high-arctic coastal marine sediment, Young Sound, Northeast Greenland. Mar Ecol Prog Ser 175:261-276

Rysgaard S, Nielsen TG, Hansen BW (1999) Seasonal variation in nutrients, pelagic primary production and grazing in a high-arctic coastal marine ecosystem, Young Sound, Northeast Greenland. Mar Ecol Prog Ser 179: $13-25$

Rysgaard S, Kühl M, Glud RN, Hansen JW (2001) Biomass, production and horizontal patchiness of sea ice algae in a high-Arctic fjord (Young Sound, NE Greenland). Mar Ecol Prog Ser 223:15-26

Sand-Jensen K, Revsbech NP (1987) Photosynthesis and light adaptation in epiphyte-macrophyte associations measured by oxygen microelectrodes. Limnol Oceanogr 32: 452-457

Schreiber U (1994) New emitter-detector-cuvette assembly for measuring modulated chlorophyll fluorescence of highly diluted suspensions in conjunction with the standard PAM fluorometer. Z Naturforsch 49c: 646-656

Schreiber U, Schliwa U, Bilger W (1986) Continuous recording of photochemical and non-photochemical chlorophyll fluorescence quenching with a new type of modulation fluorometer. Photosynth Res 10:51-62

Schreiber U, Bilger W, Neubauer C (1994) Chlorophyll fluorescence as a non-intrusive indicator for rapid assessment of in vivo photosynthesis. In: Schulze HD, Caldwell MM (eds) Ecophysiology of photosynthesis. Ecological studies, Vol. 100. Springer-Verlag, Berlin, p 49-70

Schreiber U, Hormann H, Neubauer C, Klughammer C (1995) Assessment of photosystem II photochemical quantum yield by chlorophyll fluorescence quenching analysis. Aust J Plant Physiol 22:209-220

Schreiber U, Kühl M, Klimant I, Reising H (1996) Measurement of chlorophyll fluorescence within leaves using a

Editorial responsibility: Otto Kinne (Editor),

Oldendorf/Luhe, Germany modified PAM fluorometer with a fiber-optic microprobe. Photosynth Res 47:103-109

Schreiber U, Gademann R, Ralph PJ, Larkum AWD (1997) Assessment of photosynthetic performance of Prochloron in Lissoclinum patella in hospite by chlorophyll fluorescence measurements. Plant Cell Physiol 38:945-951

Serodio J, da Silva JM, Catarina F (1997) Nondestructive tracing of migratory rhythms of intertidal benthic microalgae using in vivo chlorophyll a fluorescence. J Phycol 33: $542-553$

Smith REH, Herman AW (1991) Productivity of sea ice algae: in situ vs. incubator methods. J Mar Syst 2:97-110

Steneck RS (1986) The ecology of coralline algal crusts: convergent patterns and adaptive strategies. Annu Rev Ecol Syst 17:273-303

Trodahl HJ, Buckley RG, Vignaux M (1989) Anisotropic light radiance in and under sea ice. Cold Reg Sci Technol 16: 305-308

Van Kooten O, Snel JFH (1990) The use of chlorophyll fluorescence nomenclature in plant stress physiology. Photosynth Res 25:147-150

Webb WL, Newton M, Starr D (1974) Carbon exchange of Alnus rubra: a mathematical model. Oecologia 17:281-291

Weeks WF, Ackley SF (1982) The growth, structure and properties of sea ice. CRREL Monog. 82-1, Cold Region Research Engineering Labaratory, Hanover, NH

Wenzhöfer F, Holby O, Glud RN, Nielsen HK, Gundersen JKG (2000) In situ microsensor studies of a shallow water hydrothermal vent at Milos (Greece). Mar Chem 69:43-54

White AJ, Critchley C (1998) Rapid light curves: a new fluorescence method to assess the state of the photosynthetic apparatus. Photosynth Res 1-11

Wiggert J, Dickey T, Granata T (1994) The effect of temporal undersampling on primary production estimates. J Geophys Res 99(C2):3361-3371

Submitted: November 6, 2000, Accepted: February 12, 2001 Proofs received from author(s): October 31, 2001 